\title{
GCU
}

Glasgow Caledonian

University

University for the Common Good

\section{Viral pathogens: what are they and do they matter?}

Scobie, Linda; Crossan, Claire; Mourad, Nizar I.; Galli, Cesare; Perota, Andrea; Gianello, Pierre

Published in:

Xenotransplantation

DOI:

10.1111/xen.12412

Publication date:

2018

Document Version

Author accepted manuscript

Link to publication in ResearchOnline

Citation for published version (Harvard):

Scobie, L, Crossan, C, Mourad, NI, Galli, C, Perota, A \& Gianello, P 2018, 'Viral pathogens: what are they and do they matter?', Xenotransplantation, vol. 25, no. 3. https://doi.org/10.1111/xen.12412

\section{General rights}

Copyright and moral rights for the publications made accessible in the public portal are retained by the authors and/or other copyright owners and it is a condition of accessing publications that users recognise and abide by the legal requirements associated with these rights.

Take down policy

If you believe that this document breaches copyright please view our takedown policy at https://edshare.gcu.ac.uk/id/eprint/5179 for details of how to contact us. 
Special Issue Title/Topics: Viral Pathogens: What Are They and Do They Matter?

Guest Editor Leo Buhler

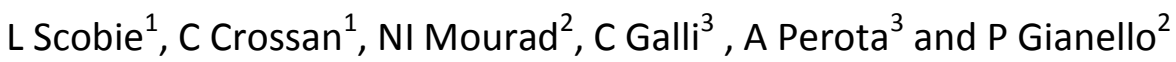

${ }^{1}$ Department of Biological and Biomedical Sciences, School of Health and Life Sciences, Glasgow Caledonian University, Glasgow, G4 OBA, U.K,

${ }^{2}$ Laboratoire de Chirurgie Expérimentale et Transplantation, Université Catholique de Louvain, 1200 Brussels, Belgium.

${ }^{3}$ Avantea, Cremona, Italy

Corresponding Author Linda Scobie

Corresponding Author Address:

Department of Life Sciences

School of Health and Life Sciences

T: +44 (0)141331 8534 | F: +44 (0)1413313208 | E: linda.scobie@gcu.ac.uk

Glasgow Caledonian University, 70 Cowcaddens Road, Glasgow, G4 OBA,

Scotland, United Kingdom 
It is well established that allo-transplantation is associated with the transfer of infectious agents ; indeed management of transplant infectious risk developed in parallel with other developments in the field. Allo-transplantation has its inherent specific infection-related problems, and the citeria for use of infected organs is changing due to the lack of donors, the improvements in anti-viral agents and testing tools. Based on these developments, the use of organs with either 'high' or 'increased' infectious risk has become more acceptable $[1,2]$.

$[1,2]$. We are aware that there are animal reservoirs of human disease leading to zoonotic infections, and pigs as donors in xenotransplantation are no exception. Considering allotransplantation and the other safety considerations voiced by the FDA at the IXA 2017 symposium [3] it is paramount that pathogens present drive the risk assessment and safety for the recipient. With this in mind, there are criteria that need to be met in order to ensure the safety of any recipient from potential pathogens present in a xenograft .

Two main issues are required to be addressed for safety; source donor animal testing and recipient monitoring. For our purposes, we report on the work we have done to address a number of safety issues in relation to islet cell transplantation and some of the issues raised in relation to the updated FDA guidance for xenotransplantation [4]

There are numbers of documents providing guidance including the consensus statements by experts published in the Xenotransplantation journal and the FDA updated guidance released in December 2016 mentioned above; it is clear that testing for pathogens is a primary objective for safety [5-7]. This includes the demonstration of a lack of pathogens/contamination at several points in the product preparation process. Due to 
conflicting issues with the concept of a specified 'list', considerations should be given with respect to testing; this includes the geographical location of the donor animals, the product being tested, the degree of immune suppression and the availability of validated diagnostics - Use of donors reared in barrier facilities under designated pathogen-free conditions should be agreed with the above in mind, and this is required to reduce risk, as not all pathogens of concern in xenotransplantation are part of standard testing [8]. It should be noted that most of these 'lists' of pathogens for testing and/or exclusion are created by experts in the field, from advisory boards to clinical application with specific purposes in mind $[7,9-11]$. For example, the specific exclusion list from the donor animals used by the Living Cell Technologies (now Diatranz Otsuka Ltd) for clinical trials in islet xenotransplanrtation $[11,12]$ is very different from the 4 checkpoint programme for comprehensive testing throughout the manufacturing process of encapsulated islets including the final product [10].

One area of controversy which continues to be discussed is the transfer of infectious microorganisms to the recipient, but it is clear that many can be eliminated via the husbandry process. The risk associated with PERV has also been debated with regard to the potential of infection in vivo that appears much less than initially thought; a number of publications have questioned whether PERV is indeed even a risk anymore $[13,14]$ Indeed, recently there has been a call for regulatory authorities to reconsider their guidance with respect to this evidence [15]. Given recent publications that have inactivated PERV in cells and pigs using CRISPR-Cas9 technology $[16,17]$, this raises the question as to why inactivation would indeed be required if risk is low? Inactivation/inhibition is seen as an additional strategy for safety [13] but could this be another reconsideration with respect to 
the difference between cell xenotransplantation and organ xenotransplantation? The final point to make is, given that editing requires constitutive expression over a period of several weeks, does this introduce another risk, i.e., activation of other genes during this period? How is this to be evaluated? This approach should be balanced with the fact that PERV has not been transferred in vivo with the selected pig lines used $[16,18]$.

We have known and unknown infectious agents to consider, so to try to address all aspects of the guidance and these testing requirements. Under the Xenoislet programme (EU FP7 project number 601827 - co-ordinator P Gianello) we have adressed the question of safety in donor animals and encapsulated islet cells by pathogen testing at the respective checkpoints. The aim was to identify suitable animals to establish a founder line for islet xenotransplantaton by 1 ) assessing the pathogen status of all source animals; advise selection of breeding animals that are free from designated pathogens and meet the criteria for PERV status, and 2) product testing, to evaluate the level of protection from pathogen contamination offered by the alginate macroencapsulation device (MCD), to evaluate pathogen status of the product and to develop sensitive and reproducible assays.

We identified 9 animals out of 392 analysed that met criteria previously described and would be suitable to take forward; PERV-C env PCR negative, low PERV-A and PERV-B copy number ( $<30$ PCR copies per genome) and no in vitro transmission during cell culture with both human HEK293 and ST-IOWA cells. 4/9 animals were found positive for porcine Cytomegalovirus, however, if animals are to be cloned, then this virus is not an issue when a skin biopsy is utilised; in additon, husbandry procedures involving hysterotomy derivation of the offspring is a suitable approach to eliminate this pathogen [6]. Looking at the pathogen status in the cell product, PERV RNA was located the endocrine fraction of the pancreas and 
neonatal islets had signficantly lower levels of PERV RNA than adult islets [19]. In addition, PERV RNA expression did not change over the neonatal islet cell 8 day-culture and maturation period [19]. This raises questions as to whether PERV replication is restricted in some way in islet cells compared to PBMC. We also tested the islet cells for other pathogens and found them to be negative compared to the positive findings in the donor animal in both neonatal and adult derived peripheral blood mononuclear cells (PMBC) [20].

Finally, we investigated the possibility of the prevention of PERV release from the alginatebased MCD. Our preliminary study suggests that the alginate is sufficient to significantly reduce PERV transmission and may be a suitable barrier for other pathogens too [21]. PERV transmission from free and encapsulated islet cells was assessed using the animal model in nonhuman primates (NHP). We understand the limitations of this model due to the lack of receptors to fully demonstrate PERV transmission, however, interestingly, we found that in animals receiving free islets, we could detect porcine micro-chimerism but not in those receiving encapsulated islets (C Crossan; unpublished data).

In summary, with respect to islet cells, neonatal pig islets have lower levels of PERV RNA than adult islets; the mechanism is unknown. Pathogens present in the donor animals do not appear to be present in islets and there are indications that the alginate MCD is protective against the release of PERV in vitro. Irrespective of the multi-level testing strategy chosen, testing of the end product is an important requirement given differences observed. As encapsulation would also reduce the use of immunosuppression, can encapsulated islets be considered low risk? Does this data support moving islets to the clinic? 
Finally, we need to consider testing in recipients. PERV testing for recipients as defined by FDA CBER 2016 section X:F [4] is as follows:

1) PCR of recipient's PBMC for PERV DNA sequence, 2) serologic analysis for PERV-specific antibodies, and 3) assays capable of detecting plasma virions, such as RT-PCR for detection of viral RNA or highly sensitive methods for detection of RT activity. Sensitive assays are not available commercially, and consistency for testing is required alongside validated assays and by recognised laboratories using suitable donor and archived samples. In addition to PERV, we need to think about the evaluation of infectious syndromes in recipient; including exclusion of common infections, assessment of other recipients from same donor source or herd, evaluation of contacts and investigation for organisms not previously associated with clinical syndromes in humans. This can be followed by the use of questionnaires [7].

It is suggested that testing is based on the Precautionary Principle: "The risk of xenogeneic infection is generally thought to be low but the deployment of appropriate procedures and assays should not wait until a risk is confirmed".[7] However this is not a scientifically based approach. With respect to PERV, the evidence does indeed demonstrate the risk is minimal.

Pathogen contamination of porcine derived products still in use have yet to reveal any adverse events related to those products. There are a number of in vivo trials to date, even though the emerging risk is still unclear there is no evidence of cross species infection via known micro-organisms [11, 22-25]. In addition, in the event of detection, PERV is susceptible to anti-virals[26]. Given the current status of xenotransplantation, the risk of transmission appears to be low and not greater than that seen for allo-transplantation: pre- 
clinical screening would reduce the risk further suggesting we may have already met the stringency criteria for 'first-in-man' studies. In fact, this is a misnomer as we already have seen clinical trials utilsing pig tissues. However, the risk is not zero. So to conclude, we have defined pathogens of risk as suggested by experts in the field of xenotransplantation but with respect to " Do they matter?" Then the simple answer is yes! 
Acknowledgements:

This work was supported by a European Commission FP7 funded project XENOISLET (project number 601827). 
References:

1. Irwin, L., et al., Utilization of increased risk for transmission of infectious disease donor organs in solid organ transplantation: Retrospective analysis of disease transmission and safety. Transpl Infect Dis, 2017. 19(6).

2. Fishman, J.A., Infection in Organ Transplantation. Am J Transplant, 2017. 17(4): p. 856-879.

3. Cooper, D.K.C., et al., Miscellaneous. Xenotransplantation, 2017. 24(6).

4. Food and Drug Administration. Guidance for industry: source animal, product, preclinical, and clinical issues concerning the use of xenotransplantation products in humans. 2003, updated 2016.

https://www.fda.gov/downloads/biologicsbloodvaccines/quidancecompliancerequlatoryinfo rmation/guidances/xenotransplantation/ucm533036.pdf. Accessed June 13, 2017. 2016.

5. Denner, J., et al., First update of the International Xenotransplantation Association consensus statement on conditions for undertaking clinical trials of porcine islet products in type 1 diabetes--Chapter 5: recipient monitoring and response plan for preventing disease transmission. Xenotransplantation, 2016. 23(1): p. 53-9.

6. Spizzo, T., et al., First update of the International Xenotransplantation Association consensus statement on conditions for undertaking clinical trials of porcine islet products in type 1 diabetes--Chapter 2a: source pigs--preventing xenozoonoses. Xenotransplantation, 2016. 23(1): p. 25-31.

7. Fishman, J.A., L. Scobie, and Y. Takeuchi, Xenotransplantation-associated infectious risk: a WHO consultation. Xenotransplantation, 2012. 19(2): p. 72-81.

8. Denner, J., Paving the Path toward Porcine Organs for Transplantation. N Engl J Med, 2017. 377(19): p. 1891-1893.

9. Onions, D., et al., An approach to the control of disease transmission in pig-to-human xenotransplantation. Xenotransplantation, 2000. 7(2): p. 143-55.

10. Gazda, L.S., et al., A comprehensive microbiological safety approach for agarose encapsulated porcine islets intended for clinical trials. Xenotransplantation, 2016. 23(6): p. 444-463.

11. Wynyard, S., et al., Microbiological safety of the first clinical pig islet xenotransplantation trial in New Zealand. Xenotransplantation, 2014. 21(4): p. 309-23.

12. Denner, J. and N.J. Mueller, Preventing transfer of infectious agents. Int J Surg, 2015. 23(Pt B): p. 306-11.

13. Denner, J., How Active Are Porcine Endogenous Retroviruses (PERVs)? Viruses, 2016. 8(8).

14. Denner, J., Is porcine endogenous retrovirus (PERV) transmission still relevant? Transplant Proc, 2008. 40(2): p. 587-9.

15. Cooper, D.K.C., et al., Regulation of Clinical Xenotransplantation-Time for a Reappraisal. Transplantation, 2017. 101(8): p. 1766-1769.

16. Guell, M., et al., PERV inactivation is necessary to guarantee absence of pig-to-patient PERVs transmission in xenotransplantation. Xenotransplantation, 2017. 24(6).

17. Yang, L., et al., Genome-wide inactivation of porcine endogenous retroviruses (PERVs). Science, 2015. 350(6264): p. 1101-4.

18. Scobie, L., J. Denner, and H.J. Schuurman, Inactivation of porcine endogenous retrovirus in pigs using CRISPR-Cas9, editorial commentary. Xenotransplantation, 2017. 24(6).

19. Mourad, N.I., et al., Characterization of porcine endogenous retrovirus expression in neonatal and adult pig pancreatic islets. Xenotransplantation, 2017. 24(4).

20. Crossan, C., et al., Examining the potential for porcine-derived islet cells to harbour viral pathogens. Xenotransplantation, 2017.

21. Crossan, C., Mourad N, Gianello P and Scobie L, Xenotransplantation, 2018(In Revision). 
22. Morozov, V.A., et al., No PERV transmission during a clinical trial of pig islet cell transplantation. Virus Res, 2017. 227: p. 34-40.

23. Scobie, L., et al., Long-term IgG response to porcine Neu5Gc antigens without transmission of PERV in burn patients treated with porcine skin xenografts. J Immunol, 2013. 191(6): p. 290715.

24. Paradis, K., et al., Search for cross-species transmission of porcine endogenous retrovirus in patients treated with living pig tissue. The XEN 111 Study Group. Science, 1999. 285(5431): p. 1236-41.

25. Di Nicuolo, G., et al., Long-term absence of porcine endogenous retrovirus infection in chronically immunosuppressed patients after treatment with the porcine cell-based Academic Medical Center bioartificial liver. Xenotransplantation, 2010. 17(6): p. 431-9.

26. Denner, J., Can Antiretroviral Drugs Be Used to Treat Porcine Endogenous Retrovirus (PERV) Infection after Xenotransplantation? Viruses, 2017. 9(8). 